\title{
WHY NATIONALISM
}

\author{
Karel J. Leyva \\ Université de Montréal \\ karelj.leyva@gmail.com
}

Reseña de: TAMIR, Yael (2019). Why Nationalism. New Jersey: Princeton

University Press, 205 págs.

Durante los últimos treinta años, los nacionalistas liberales han defendido la idea según la cual del mismo modo que el liberalismo necesita del nacionalismo para lograr mejor sus objetivos centrales, las diferentes expresiones del nacionalismo deben ser limitadas por los principios liberales. Yael Tamir ha sido una de las figuras clave de esta singular articulación. En su obra Liberal Nationalism (1993), como en sus trabajos posteriores, no sólo defendió que era posible conciliar los valores liberales con ciertos aspectos fundamentales de la tradición nacionalista, sino también que era necesario fundar una alianza entre el liberalismo y el multiculturalismo con el propósito de hacer justicia a los miembros de las minorías culturales y religiosas.

En Why Nationalism, su más reciente libro, Tamir se propone enumerar las ventajas que el nacionalismo aporta al discurso político y examinar una variedad de reivindicaciones nacionales juzgándolas por sus propios méritos. Tamir lleva a cabo su propuesta sin importar que tales reivindicaciones puedan estar asociadas a personalidades políticas problemáticas, considerando que, del mismo modo que el nacionalismo puede tener consecuencias devastadoras y destructivas, también puede ser una fuerza política constructiva y creadora. Asociar el nacionalismo exclusivamente a un conjunto de ideas reaccionarias o identificarlo con sentimientos tribales, pasando por alto sus poderes modernizadores y liberadores representa, según Tamir, una profunda incomprensión del mundo moderno, o quizá una postura destinada a desacreditarlo. Cierto, el nacionalismo puede presentarse como reaccionario y populista. Sin embargo, "el nuevo nacionalismo" es mucho más que eso: es una expresión de una voz que refleja la creciente brecha entre el pueblo y unos pocos privilegiados, así como la ira inspirada por las crecientes desigualdades. Esta voz colérica debe ser tenida en cuenta para revisar el orden mundial actual y hacer que funcione en beneficio de la mayoría. En el mundo desarrollado, el péndulo político se ha inclinado demasiado hacia el polo individualista, ignorando generaciones que sufren de alienación social y anonimato, a la vez que el péndulo económico se ha movido hacia el lado del libre mercado, dejando vulnerables a demasiados individuos. Tales transformaciones del panorama social y político plantean nuevos desafíos y exigen nuevas respuestas. 
Tamir identifica dos formas actuales bajo las cuales se presenta el nacionalismo. La primera es aquella que puede encontrase en Cataluña, Lombardía y Véneto, así como en Flandes, Transilvania, Escocia o Kurdistán. Este tipo de nacionalismo representa el deseo de grupos nacionales de exigir el autogobierno. Tales movimientos nacionales tratan de reclutar el mayor número posible de conciudadanos y son inclusivos interiormente en la medida en que intentan fomentar una asociación entre las élites, las clases medias y las clases trabajadoras para respaldar el programa nacional separatista. Sin embargo, este nacionalismo tiende a erosionar la solidaridad cívica del Estado-nación. De hecho, su origen se encontraría, al menos en parte, en el debilitamiento del Estado-nación moderno, que ha sucumbido a las presiones tanto del globalismo como del localismo. Cuando el poder político se erosiona, nos dice Tamir, y el Estado se enfrenta a una crisis de legitimación, los miembros de las naciones minoritarias se ven atraídos a cuestionar el (c)statu quo nacional/político existente. A diferencia del nuevo tipo de nacionalismo, que veremos enseguida, este nacionalismo no busca entonces fortalecer el Estado-nación, sino aflojar los marcos políticos existentes y retomar las exigencias de autodeterminación nacional. Puesto que tales naciones habitan un territorio distinto y comparten una historia, una cultura y un idioma comunes, sus miembros recurren a su identidad distintiva para justificar su demanda de autogobierno. Sin embargo, la historia de las pequeñas naciones habría dejado claro que los argumentos nacionales no pueden sobrevivir por sí solos, pues su poder proviene de la capacidad de servir a las necesidades del Estado moderno, cuyo funcionamiento depende de su aptitud para formar una economía considerable, tener fronteras defendibles y fomentar una vida cultural próspera. Y aunque las aspiraciones de separatismo llegaron para quedarse, Tamir estima que su efecto en futuros eventos políticos será mucho menos significativo que los del nuevo tipo de nacionalismo.

El segundo tipo de nacionalismo, que constituye el eje central del libro, es el nacionalismo de los vulnerables: el nacionalismo de los menos favorecidos por el proceso de hiperglobalización. Los vulnerables se apoyan en los sentimientos nacionales para convencer a las élites de poner a su nación en primer lugar y, puesto que no habitan en un territorio definido o tienen una identidad distintiva, se definen a sí mismos en oposición a los demás. Como lo reconoce Tamir, la distancia desde sus posiciones a un nacionalismo agresivo y xenófobo es corta. Sin embargo, a pesar del lenguaje utilizado y de la asociación de estos nacionalistas con movimientos de derecha, muchas de sus reivindicaciones tienen valor moral: lo que ellos piden, a fin de cuentas, es reescribir el contrato social de manera que responda a sus necesidades. El nacionalismo de los vulnerables sería, de hecho, una revuelta contra la traición de las elites globales. Ellos sienten, con razón según Tamir, que por el solo hecho de ser blancos, hombres y miembros de la mayoría se les trata como si tuvieran privilegios que en realidad no tienen, y que deben ceder el paso a otros que son favorecidos por las medidas de acción positiva, a la vez que sus ingresos estancan, sus hijos viven en peores condiciones y su esperanza de vida disminuye. Por estas razones, sintiéndose excluidos y desposeídos, se proponen revivir los contornos sociales en los que la nación proporcionaba una identidad bien definida y privilegiada. En similares circunstancias, el proceso de construcción nacional 
les hubiera permitido reclutar a las élites, pero hoy en día las élites están menos dispuestas a definirse en términos nacionales y han dejado tanto la terminología como los símbolos nacionales a los vulnerables. No debería sorprender que estos miembros vulnerables de las mayorías afirmen ser los verdaderos representantes de la nación.

Una de las características más sorprendentes del libro es la manera en que la retórica de Tamir, quien ha sido siempre una figura relevante del culturalismo liberal, se alinea con perspectivas conservadoras como las de Francis Fukuyama (The Demand for Dignity and the Politics of Resentment) o Mark Lilla (The Once and Future Libera) con respecto a las políticas identitarias. El surgimiento del multiculturalismo es presentado como una distracción conveniente de las élites liberales que, llamando la atención sobre las diferencias culturales se alejaron de los conflictos de clase. La adopción del multiculturalismo resultaba menos costosa que orientarse hacia un cambio social basado en las diferencias de clase. Según Tamir, los progresistas simpatizaron con aquellos argumentos que, desde los grupos minoritarios, criticaban la supuesta neutralidad del Estado, obligando a la mayoría a reconocer que las afiliaciones culturales, nacionales y lingüísticas determinan quiénes somos y lo que obtenemos. Las minorías exigieron la remodelación de la esfera pública, dando espacio a sus propias identidades particulares. La diversidad se convirtió en el grito de guerra liberal y las políticas de identidad se convirtieron en un pilar ideológico de la política del siglo XXI. Hoy, sin embargo, son los miembros menos favorecidos de la mayoría quienes protestan haciendo valer su identidad y criticando activamente una diversidad que les arrancó su estatus social, cultural y político.

Por ello, Tamir propone un nuevo contrato social. Aunque los poderes distributivos del Estado-nación se han erosionado, la homogeneidad cultural se ha puesto en tela de juicio y la solidaridad se ha desgastado, la incapacidad teórica de definir un conjunto alternativo de principios morales y políticos aplicables deja al Estado-nación como la única opción viable. El globalismo no ha podido reemplazar al nacionalismo porque es incapaz de ofrecer un programa político que satisfaga las necesidades más básicas de los individuos modernos: el deseo de ser agentes autónomos y de autogobernarse, la voluntad de vivir una vida significativa que se extienda más allá de uno mismo, la necesidad de pertenecer a una comunidad creativa, de sentirse especial, de disfrutar de la sensación de estabilidad y continuidad intergeneracional. Los sentimientos nacionales deberían utilizarse para crear la disposición a reconstruir una coalición entre clases que ofrezca a los individuos razones valiosas para trabajar juntos, promover el bien común y asegurar una distribución más justa de los riesgos y oportunidades.

Cuatro son las medidas propuestas por Tamir para domar el nuevo nacionalismo y hacerlo más liberal y tolerante. En primer lugar, es necesario poner el país en primer lugar, sin que esto signifique adoptar un sentido de superioridad, pues los demás países tienen el mismo derecho y deber de perseguir sus propios objetivos. Se trataría de un nacionalismo liberal basado en los derechos nacionales universales que no da la espalda al mundo, sino que utiliza la nación como trampolín desde el que se puede saltar a un 
mundo mejor gobernado. Para ello, es necesario que los Estados-nación se comprometan nuevamente a construir la nación, dado que es imposible prosperar sin inversión social, cultural y política. Se trata de entender que las afiliaciones nacionales se basan en la cultura, las tradiciones, el idioma, los principios políticos, la historia e incluso la religión. Estas características "unificadoras" deben ser explicadas en detalle y hacerlas evidentes por medio de la educación y el discurso público. En segundo lugar, dado que ningún país es cultural, étnica o religiosamente homogéneo, el lugar de las minorías debe ser asegurado. El hecho de que los miembros de las minorías culturales no compartan el espíritu, la cultura o el idioma nacional dominante no debe ser usado en su contra. Los derechos y opciones de los demás deben consolidarse internamente en la misma medida en que se respetan internacionalmente. La necesidades sociales, económicas y culturales de los vulnerables deben ser satisfechas sin cultivar el miedo y el odio. El fomento de la identidad nacional debe complementarse con el fomento activo de la empatía con los ciudadanos que no son compatriotas nacionales (citizens who are not fellow nationals). Tamir propone reforzar el énfasis en el papel del Estado como patria en lugar de negar la base contractual del Estado y los beneficios que conlleva. Los autóctonos, las minorías, los inmigrantes o los extranjeros tienen derecho a ser defendidos y respetados: el nacionalismo liberal no ignora el papel de la identidad y la pertenencia y está intrínsecamente atento a las desventajas que representa pertenecer a ser una minoría y busca por tanto formas de mejorarlas. En tercer lugar, los riesgos y oportunidades sociales deben distribuirse de manera justa y transparente. Las cargas y beneficios resultantes de las políticas adoptadas, (sean políticas de inmigración generosas o cambios en las estructuras económicas) deben distribuirse de manera que mejoren la suerte de los débiles y limiten el poder de los privilegiados. En último lugar, sin que por ello sea menos importante, es necesario reavivar un sentido de orgullo colectivo, así como de optimismo social y político que permita prever un futuro mejor para las sociedades, los individuos y las generaciones venideras.

Tanto el neoliberalismo brutal como el nacionalismo xenófobo, concluye Tamir, deben ser refrenados, equilibrados, ajustados y reformados para satisfacer las necesidades del siglo XXI. El nacionalismo, no debe ser dejado en manos de los extremistas. Los demócratas liberales, los socialdemócratas y todo aquel que busque justicia deben encauzar el nacionalismo creando un orden social más justo, cerrando las brechas socioeconómicas y proporcionando a la gente una referencia cultural y normativa con la que vivir.

En Why Nationalism, Tamir adopta una perspectiva que integra elementos provenientes de diferentes escuelas de pensamiento, quizá con la esperanza de generar un cierto consenso en torno a su proposición normativa. Al hacerlo, sin embargo, no puede evitar ciertas disonancias cognitivas, como el hecho de sumarse a quienes critican las políticas de identidad y a la vez proponer mejorar las condiciones de aquellos a quienes están destinados tales políticas, sin ofrecer opción de recambio. El libro presenta algunos problemas que necesitarían más espacio del que dispongo aquí para discutirlos, de modo que me limitaré a esbozar algunos de ellos brevemente. El primero es que Tamir 
no discute ninguna alternativa a su posición y, quizá por ello, no logra demostrar que el nacionalismo sea la mejor base para las democracias liberales contemporáneas. El segundo problema consiste en que, aunque el rol de la educación en los procesos de construcción nacional es abordado en el texto, Tamir no considera siquiera que la educación puede constituir un elemento fundamental para favorecer la cohesión social en las sociedades pluriculturales. Un tercer problema es que el nacionalismo, tal y como se presenta en el libro, establece una distinción radical entre los nacionales y los demás (inmigrantes, miembros de minorías étnicas, etc.) y pasa por alto los compromisos que los llamados inmigrantes de segunda y tercera generación establecen entre la nación y la cultura heredada de sus ancestros. Otro problema es que Tamir presenta una visión acrítica de los sentimientos de exclusividad que experimentan los miembros de las mayorías nacionales y justifica la interpretación edulcorada que ellos dan a ciertos eventos sombríos de la historia nacional. Finalmente, Tamir, quien se refiere en gran medida al contexto norteamericano, mantiene una concepción idealizada de los beneficios de la nación, por ejemplo, cuando arguye que los procesos de construcción nacional beneficiaron a todos de igual manera, como si pudiera establecerse un equivalente entre los beneficios recibidos por los hombres blancos norteamericanos y los miembros de las comunidades afroamericanas. El libro pasa por alto las dinámicas de dominación (interculturales, patriarcales, etc.) que limitan la autonomía de algunas categorías de individuos y omite tanto las razones que llevaron a adoptar ciertas políticas multiculturales como el impacto de estas políticas en los valores democráticos. Cierto, la vulnerabilidad de los miembros de las mayorías nacionales tiene peso moral, pero tal peso no es superior al de la vulnerabilidad del resto de los ciudadanos.

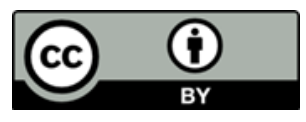

